\section{International Scientific Journal Theoretical \& Applied Science}

\author{
p-ISSN: 2308-4944 (print) e-ISSN: 2409-0085 (online) \\ Year: $2018 \quad$ Issue: $01 \quad$ Volume: 57 \\ Published: $30.01 .2018 \quad$ http://T-Science.org
}

Vladimir Nikolaevich Medvedev
The Teacher Department of Navigation,
The Engineer-mechanic,

State Maritime University Admiral Ushakov, Russia, medvedevsail@gmail.com

SECTION 21. Pedagogy. Psychology. Innovation in Education

\title{
YACHTING - THE GENERALIZED CONDITION OF FORMING OF THE COMPLETE AND SYSTEM IDENTITY OF THE WIDE-PROFILE SEA SPECIALIST
}

Abstract: The basic principles of building an educational system of students engaged in yachting are considered; reveals the increasing role of students in yachting in the system of maritime vocational education and the lack of development of their practical organizations; analysis of the need for modern society in students with highly developed professional qualities and insufficient use of educational opportunities for yachting; shows the need to develop the professional qualities of students and the insufficiently developed scientific and methodological support of the basics of practical yachting.

Key words: forming of the personality, students, yachting, professional education, practical organization, naval fleet.

Language: Russian

Citation: Medvedev VN (2018) YACHTING - THE GENERALIZED CONDITION OF FORMING OF THE COMPLETE AND SYSTEM IDENTITY OF THE WIDE-PROFILE SEA SPECIALIST. ISJ Theoretical \& Applied Science, 01 (57): 137-144.

Soi: http://s-o-i.org/1.1/TAS-01-57-25 Doi: crossef https://dx.doi.org/10.15863/TAS.2018.01.57.25

УДК 372.851

\section{ЯХТИНГ - ОБОБЩЁННОЕ УСЛОВИЕ ФОРМИРОВАНИЯ ЦЕЛОСТНО-СИСТЕМНОЙ ЛИЧНОСТИ ШИРОКОПРОФИЛЬНОГО МОРСКОГО СПЕЦИАЛИСТА}

Аннотация: рассмотрены основные принцииы построения воспитательной системы студентов, занимающихся яхтингом; раскрывается возрастающая роль занятий студентов яхтингом в системе морского профессионального образования и недостаточная разработанность их практических организаций; анализируется потребность современного общества в студентах с высокоразвитыми профессиональными качествами и недостаточное использовании воспитательных возможностей занятий яхтингом; показывается необходимость развития профессиональных качеств студентов и недостаточная разработанность научно-методического обеспечения основ практических занятий яхтингом.

Ключевые слова: формирование личности, студенты, яхтинг, профессиональное образование, практическая организачия, морской флот.

\section{Introduction}

Формирование целостно-системной личности широкопрофильного морского специалиста - процесс, в ходе которого он приобретает профессионально важные знания, навыки, качества. Условием успешного формирования целостно-системной личности студента является его положительное отношение к учебе, установленным порядкам в вузе, научно оправданная организация его деятельности, выполнение задач, упражнений, создание обстановки для наиболее интенсивного проявления и совершенствования профессионально важных знаний, навыков, умений, психических процессов, личных качеств. Обобщенно можно выделить три группы психологических условий успешного формирования целостно-системной личности студента в вузе: со стороны студентов; со 
стороны преподавателей, руководителей; со стороны их совместной деятельности. Студента как личность формирует вся сумма влияний, которым он подвергается: организация учебы, занятия по различным предметам, личный пример преподавателя, руководителя, отношение товарищей. Будучи взаимно связанными, все качества формируются в органическом единстве. [4].

\section{Materials and Methods}

Яхтинг можно рассматривать как важный психолого-педагогический ресурс для приобретения морскими специалистами определенного жизненного и практического опыта, воспитания целостно-системной личности, реализации ими своего творческого потенциала, развития нравственных ценностей: поддержка, чувство локтя, взаимопомощь, дружба; а также системного восприятия будущей профессиональной деятельности, способствует развитию мотивации углубления знаний в профессиональной деятельности. Выделение антропоориентированного,

аксиологического и деятельностного подходов в качестве методологических оснований исследования позволило определить важные положения, связанные с осознанием человека как сознательного, активно действующего участника социальных процессов, ответственного за результаты своей деятельности, как основы полноценного развития целостно-системной личности широкопрофильного морского специалиста. [3].

Занятия яхтингом в вузе могут быть эффективным ресурсом личностного развития будущих студентов - специалистов широкого профиля при условии:

- насыщения предметов блока специальных и общепрофессиональных дисциплин смыслами яхтинга;

- изменения характера содержания и организации учебных практик студентов плавательных специальностей морских вузов; организации яхтенного сообщества единомышленников, объединенного общим смыслом, возможностью осуществлять социально значимую деятельность в вузе.

В рамках теоретического исследования выявлены педагогические условия, при которых занятия яхтингом будут являться ресурсом личностного развития. Таковыми являются: насыщения предметов блока специальных и общепрофессиональных дисциплин смыслами яхтинга; изменения характера содержания и организации учебных практик студентов плавательных специальностей морских вузов; организации яхтенного сообщества единомышленников, объединенного общим смыслом, возможностью осуществлять социально значимую деятельность в вузе.

Анализ результатов показал, что реализация всех трех педагогических условий приводит к позитивной динамике. Происходят изменения в ценностных ориентациях студентов, проявляющиеся в принятии ими социальных и личностных ценностей яхтинга, готовности и осознанной включенности в них. Позитивные изменения показателей второго критерия эффективности занятий яхтингом профессиональные установки - позволяют говорить об устойчивом интересе студентов к своей будущей профессиональной деятельности, изменении мотива этой деятельности (преобладание альтруистических мотивов), изменении смысловых, целевых установок. Такие показатели критериев личностного развития студентов объясняются успешной реализацией педагогических условий, активизирующих процесс влияния яхтинга на личностное развитие будущих специалистов. Таким образом, результаты, полученные в ходе опытноэкспериментальной работы, подтверждают, что яхтинг является одним из эффективных ресурсов формирования целостно-системной личности студентов.

Занятия яхтингом в системе профессионального образования также являются фактором развития социальной активности студентов при реализации следующих социальнопедагогических условий:

$\begin{array}{lrr}\bullet & \text { использование } & \text { личностно- } \\ \text { ориентированных } & \text { технологий } & \text { развития }\end{array}$ социальной активности студентов;

- свободный выбор студентами видов и форм социально значимой деятельности;

- педагогическая поддержка перехода процесса развития социальной активности в режим саморазвития за счет актуализации мотивационной сферы студентов и их выхода в рефлексивную позицию.

Модуль развития социальной активности студентов, представляет собой логически завершенную последовательность этапов личностного роста студентов, целостность которого обеспечена единством структурных (цель, принципы, содержание, технологии) и функциональных (аксиологическая, адаптирующая, передача культурного наследия, компенсаторная, регулятивная) компонентов. Данный модуль реализуется с учетом принципов добровольности, самоактуализации,

индивидуальности, субъектности, творчества и поддержки. Изучение современного состояния проблемы развития социальной активности студентов, анализ психолого-педагогический литературы, опыт работы в волонтерском движении, проведенное нами исследование 
показали, что добровольная общественная деятельность студентов сегодня не только может помочь решению многих социальных проблем общества, но и способствовать развитию социально-значимых качеств юношей и девушек, формированию у них активной жизненной позиции.

Исходя из воспитательных возможностей занятий яхтингом, на основе системного и личностно деятельностного подходов был разработан структурно - функциональный модуль развития социальной активности студентов - участников занятий яхтингом. Он характеризуется наличием пяти этапов личностного роста (выбора и самопознания, самосовершенствования, самоопределения, самореализации, творческого роста). Целостность модуля обеспечена единством структурных (цель, содержание, принципы, технологии) и функциональных (аксиологический, адаптирующий, передачи культурного наследия, компенсаторный, креативный, регулятивный) компонентов.

Яхтинг можно рассматривать как важный психолого-педагогический ресурс для приобретения студентами определенного жизненного и практического опыта, создания инновационно-творческой образовательной среды, усиления профессиональной мотивации, овладения способами

самоуправления и самообразования, создания атмосферы сотрудничества, а также воспитания профессионально значимых качеств: умение работать в коллективе, уметь подчиняться и руководить коллективом в разных обстоятельствах; а также системного восприятия будущей профессиональной деятельности, которое способствует развитию мотивации углубления знаний в профессиональной деятельности. Данная деятельность по своей природе и сущности близка профессиональной работе студентов - курсантов плавательных специальностей морских вузов и требует от ее участников проявления целеустремленности, мотивированности, самоорганизации и контроля, с принятием на себя ответственности за результат выполнения заданий.

В рамках теоретического исследования выявлены педагогические условия, при которых занятия яхтингом будут являться ресурсом развития профессиональной деятельности. Таковыми являются: психодиагностика готовности студента к восприятию высшего образования и профессиональному обучению; создание рефлексивной среды, включение студентов в ситуации, требующие многовариантного решения, а также моделирующие возможные нестандартные производственные ситуация; соотнесенность учебнопрофессиональной деятельности с реальной практикой профессиональной работы; использование коллективных форм деятельности, в которых благодаря групповой апперцепции происходит коррекция индивидуальных способов работы, а также усвоение профессиональных эталонов и образцов; снятие психологических барьеров у студентов при самоанализе своей учебно-профессиональной деятельности, организация переосмысления прошлого опыта; мотивационно-ценностное отношение к профессиональному адекватной личностной и профессиональной самооценки, самоконтроля и саморегуляции собственных действий и психических состояний; включение студентов в поисковоисследовательскую деятельность.

Для выявления эффективности названных условий теоретически обоснованы и выведены следующие критерии: ценностные ориентации студентов, личностные установки, развитие профессионально важных качеств.

Анализ эмпирических данных определил конкретную связь между факторами, условиями, предпосылками личностного развития студентов и их практической деятельностью. В результате был выделен ряд существенных закономерностей: чем глубже осмысление и принятие педагогических, психологических и профессиональных смыслов яхтинга, тем выше активная включенность студентов в эту деятельность; чем шире и разнообразнее поле занятий яхтингом, тем больше у студента возможностей приобретения субъектного профессионального опыта; чем дольше пребывание студента на борту парусной яхты, тем чаще он испытывает потребность в спонтанном проявлении навыков умения работать в коллективе, умения подчиняться и руководить коллективом в разных обстоятельствах, а также системного восприятия будущей профессиональной деятельности, которое способствует развитию мотивации углубления знаний.

Опытно-экспериментальное исследование подтвердило, что наполнение предметов блока специальных и общепрофессиональных дисциплин смыслами яхтинга, а также введение спецкурса «Факультативные занятия яхтингом» и «Азбука яхтинга» для начинающих помогают студентам осознать и принять ценности яхтинга, его гуманистическую сущность; приобрести новый социальный, эмоциональный, жизненный и профессиональный опыт взаимодействия в различных ситуациях имитирующих будущую профессиональную деятельность. У студентов 
старшего курса, углубленно занимающихся яхтингом, проявляется желание полноправно руководить студентами младших курсов в вопросах развития навыков управления яхтой и настройкой парусов, счисления и обсервации своего места положения и прокладкой курса на бумажных картах, что развивает их будущие профессиональные навыки руководителя и офицера торгового флота.

Формирование

востребованных современным рынком труда специальных технологических навыков у студентов морских высших учебных заведений является актуальной образовательной задачей, что подтверждается федеральным государственным образовательным стандартом (ФГОС). Однако анализ реальной ситуации в образовательной практики морских высших учебных заведений показывает, что в рамках занятий студенческим яхтингом сложились предпосылки для разработки вопросов условий формирования технологических компетенций будущих специалистов морской отрасли на основе задачного обучения этому виду деятельности.

Формирование

специальных технологических навыков студента - процесс, в ходе которого он приобретает профессионально важные знания, навыки и качества. Условием успешного формирования специальных технологических навыков студентов морских высших учебных заведений является внедрение в процесс изучения дисциплин профессиональных циклов занятий яхтингом. В рамках этих занятий со студентами необходимо практиковать задачное обучение, способное обеспечить целенаправленное, пошаговое приобретение специальных технологических навыков. Такая форма проведения занятий представляет собой поэтапную организацию постановки учебных задач и упражнений преподавателем; выбор способов их решения, диагностики и оценки полученных результатов студентами.

Преподаватель на яхте - капитан, иначе шкипер, а вместе со студентами - экипаж. Задача преподавателя - создание на борту учебной яхты обстановки для наиболее интенсивного проявления и совершенствования технологических навыков у экипажа. Можно выделить три группы психологических условий успешного формирования технологической деятельности студента: со стороны его личности; со стороны преподавателей, руководителей; со стороны их совместной деятельности. Технологические навыки студента во время занятий яхтингом формирует сумма влияний, которым он подвергается: организация деятельности шкипером (распределение обязанностей), занятия по различным задачам технологических компетентностей, личный пример преподавателя, руководителя, отношение к выполнению поставленных задач со стороны самого студента. Будучи взаимно связанными, все качества формируются в органическом единстве. Непрерывное самообразование, повышение профессиональной компетентности студентов, независимо от уровня получаемого образования, выступают как метод расширения их технологических навыков. Для общества непрерывное

совершенствование профессиональной

компетентности студентов становится силы, также ориентированной на непрерывное расширение «горизонтали» своей квалификации, возможности которой безграничны. [9,1].

Модель занятий студенческим яхтингом будет способствовать развитию профессиональной деятельности будущих специалистов как плавательных, так и гуманитарных специальностей, стимулировать актуализацию их технологических навыков при соблюдении совокупности педагогических условий:

- содержания видов деятельности на палубе яхты осуществляется в соответствии с показателями готовности будущего специалиста к выполнению производственно-технологической деятельности (готовность: к проектированию технологических процессов и производства; к организации и осуществлению производственнотехнологической и инновационной деятельности; к рефлексии, самоконтролю и коррекции результатов производственно-технологической деятельности);

- формирование данной компетентности происходит по следующим этапам: информационный (решение задач на выделение искомых данных, уточнение формулировок задач, установление противоречий), процессуальнообучающий (соотнесение имеющихся знаний и готовности решать задачи; использование логико-поисковых задач, ориентированных на производственную деятельность инженера), деятельностный (умения выдвигать гипотезу, находить принципы решения, соотносить их с условиями задач, поставленных производственными проблемами и ситуациями) и обеспечивается применением многоуровневых задач и заданий профессиональной направленности;

$\begin{array}{ccc}\text { - } & \text { создание } & \text { профессионально- } \\ \text { образовательной среды, } & \text { способствующей }\end{array}$ развитию технологических навыков будущего специалиста, доминирующих в производственнотехнологической деятельности, достигается путем обогащения педагогических форм производственно-технологическими задачами, характерными для общепрофессиональных 
дисциплин (изучение базы инженерной деятельности, принципов производственных процессов, теоретических основ устройства и работы оборудования). [17].

Наряду со знаниями, умениями, навыками важная роль в структуре компетентности студента отводится способности применять их в профессиональной деятельности. Любая компетентность формируется и развивается в деятельности. Яхтинг - особый вид деятельности. Он важный психолого-педагогический ресурс, который синтезирует в себе возможности развития предметных отношений профессиональных навыков студентов и одновременно представляет собой среду для приобретения ими определенного жизненного и практического опыта. Деятельность рассматривается как сложное системное образование с разными уровнями строения, функционирования и механизмами самоуправления. Выделяются такие уровни: деятельность - действия - операции психофизиологические процессы. Студент овладевает необходимыми знаниями посредством особой деятельности, организуемой в обучении и воспитании. Усвоение знаний следует организовывать как совместную деятельность обучающего и обучаемого с распределением функций между ними. У первого - функции организации, регуляции, оценки и коррекции деятельности обучаемого, у второго исполнительские функции (т.к. на начальном этапе он ещё не умеет самостоятельно организовывать свою деятельность). [2,6].

Действие в яхтинге основополагающий процесс. Морская среда сама по себе очень динамична это в равной мере переносится и на палубу парусной яхты. Ветер от природы «живой» - часто меняет направление и силу в единицу времени. Паруса зависимы от силы и направления работы ветра: не смог подстроиться под его изменение - паруса не будут иметь определенной тянущей силы, а это означает дрейф вместо движения вперёд. Соответственно увеличивается пройденное расстояние. Студенты учатся правильно ориентироваться в ситуации, требующей действия, и правильно ориентировать его исполнение - самое важное в жизни. Оснастка современной парусной яхты включает в себя множество позиций. Здесь стоячий и бегучий такелаж, паруса, блоки и лебёдки для управления бегучим такелажем и многое другое, что в целом формирует объект изучения - парусная яхта. Но это статика. Динамика, то есть движение яхты под парусами и управление ею, в целом осуществляется по законам гидравлики (все, что ниже ватерлинии: смачиваемая поверхность корпуса, форма киля, вид пера руля и т.д.) и аэродинамики (по ним работают паруса, а также влияет стоячий такелаж, экипаж, форма рубки). Результатом систематических занятий является более глубокое знание о взаимодействии целенаправленного преобразования объекта, появление соответствия понятия о нём его объективным свойствам и преобразование их в предметные знания об объекте. Знания настройки парусов на определённый курс относительно ветра и умения держать руль ровно и вести яхту по курсу на компасе выступают единым содержанием преобразовательной деятельности знания ориентируют её исполнение, а исполнение, ориентированное знаниями, является умением. [5,18].

Одним из показателей развитого мышления человека является его способность к внутреннему диалогу. Наиболее благоприятные условия для формирования внутреннего диалога представляют различные формы дополнительного образования. Разнообразие выражается в предоставлении воспитаннику возможности принять добровольное решение о предпочтении той или иной формы активности. Сама эта возможность утверждает в сознании учащегося ответственность за свою судьбу. Предполагается также его готовность к анализу ситуации, учёту различных внешних обстоятельств, своих способностей, временных возможностей и интересов. Сама процедура выбора является мощным фактором стимуляции умственной активности учащегося. [12].

Способность к самоуправлению возникает не спонтанно. Как и все высшие психические функции, эта способность развивается в результате регуляции деятельности нормами, устанавливаемыми на борту яхты. Контролирующим органом за их исполнением является шкипер. На практике, чем меньше возрастной разрыв между командой (студентами) и шкипером, тем более понятным языком друг для друга они изъясняются. Правила организации деятельности на борту яхты стандартны, а отличаются лишь внешними условиями на них оказываемыми (штиль, свежий ветер, шторм). В быстроизменяющихся условиях деятельности слаженнее работает та команда, в которой навыки применяются на рефлексивном уровне и где от момента подачи команды шкипером до её исполнения проходит минимальное количество времени. [7,8].

Итак, предметные отношения в жизнедеятельности студентов имеют два направления: предметно-деятельностное и предметно-социальное. Первое рассматривает и обобщает статические знания о яхте в целом: её устройстве, оснастке стоячего и бегучего такелажей (такелажные работы); виды парусов и их оснастка; работа с картами (навигация и лоция); метеорология, курсы относительно ветра 
и настройка яхты на них и прочие судоводительские, судомеханические, радионавигационные и даже медицинские знания необходимые для успешного и безопасного плавания. Второе направление в динамике обобщенно рассматривает яхтенную команду (экипаж): её внутреннее взаимодействие в различных метеорологических (выпадение осадков, ветровых, волновых) условиях; распределение ролей (обязанностей: работа на баке, мачте, шкотах стакселя, шкотах грота, а в крейсерском плавании добавляется вахта на камбузе и приборка салона); чёткая иерархия взаимоотношений и субординация, особенно в экстремальных условиях (взаимодействие капитана, старшего помощника и студентовматросов в соответствии с должностями в судовой роли). Для того чтобы рулевой мог получить максимум отдачи от экипажа и наоборот, между ними должно быть истинное содружество: матрос должен удовлетворять требованиям рулевого, а рулевой - стремиться к тому же для матроса. В слаженном экипаже буквально по мимике и жестам происходит взаимопонимание и взаимодействие между членами команды. В народе про это говорят, они «понимают друг друга с полуслова».

Контроль знаний и умений студентов — один из важнейших элементов учебного процесса. От его правильной организации зависит эффективность управления учебновоспитательным процессом и качество подготовки студентов. Процесс обучения хождению под парусом не может быть полноценным без регулярной и объективной информации о том, как усваивается студентами материал, как они применяют полученные знания при работе с парусами и снастями на разных курсах относительно ветра при различной его силе. При этих взаимодействиях устанавливается «обратная связь», которая позволяет оценивать динамику усвоения учебного материала, действительный уровень владения системой знаний, умений, навыков. При этих условиях самоконтроль знаний и умений у студентов выполняет проверочную, обучающую, развивающую, воспитательную и методические функции одновременно, но наиболее важная и специфическая проверочная функция. Показатели контроля служат главным основанием для суждения о результатах работы с парусами, т.е. для решения таких вопросов, как изменение курса относительно ветра, изменение настроек шкотов или стоячего такелажа, а также постановка и уборка парусов в данных погодных условиях. Обучающая функция - другое важное предназначение контроля. В ходе выполнения контрольных заданий адресованных шкипером для студентов происходит повторение и закрепление, совершенствование приобретенных ранее знаний путем их уточнения и дополнения, студенты переосмысливают и обобщают пройденный материал, используют знания в практической деятельности. Контроль способствует формированию умений и навыков рационально организовывать учебную деятельность, самостоятельно овладевать знаниями. [1,11].

Контроль дает необходимый учебный и воспитательный эффект при соблюдении ряда требований. Он должен быть: планомерным и систематическим, т.е. осуществляться в соответствии с запланированным ходом учебновоспитательного процесса, составлять его органическую часть и строиться на основных вопросах программы обучения. Контроль всесторонний, т.е. наиболее полно выявляющий фактический уровень усвоения студентами учебной информации, охватывающий все разделы программы, обеспечивающий проверку не только предметных знаний, но и усвоение мировоззренческих идей, общеучебных и специальных умений и навыков. Контроль индивидуальный - процесс овладения знаниями и умениями. Каждый студент овладевает знаниями и умениями в соответствии со своими внутренними психолого-физиологическими особенностями. Ко всем студентам необходимо предъявлять одинаковые требования в отношении объема знаний, уровня сформированности умений, но иногда необходимо принимать во внимание такие индивидуальные качества студентов, как природную медлительность, робость, застенчивость, излишнюю самоуверенность, физические недостатки. Контроль должен быть педагогически тактичным - осуществляться в спокойной деловой обстановке. Не следует торопить студентов с действием или переключать их на другой процесс в ходе выполнения конкретно-указанного самим же преподавателем действия.[19].

В теории образовательных систем контроль рассматривается как операция сопоставления запланированного результата с эталонными требованиями и стандартами, а оценка - как сопоставление полученного результата с поставленной целью по заранее установленным критериям. В то же время результат любой деятельности, в том числе учебной, требует осмысления, сравнения, оценки исходных и конечных состояний, для студента это осмысление должно выражаться следующими вопросами: «Достигнута ли учебная цель?», «Если нет, то почему и какова тогда степень частичного достижения цели?», «Если результаты превзошли поставленную цель - то 
почему и в какой степени?», «Удалось ли реализовать все задачи, составляющие в совокупности поставленную цель?», «Какие задачи оказались нерешенными и почему?», «Что необходимо усовершенствовать, чтобы их все же решить?», «Какой опыт приобретен в процессе достижения учебной цели, и как он может быть полезен в дальнейшем?» и так далее. Научить студентов каждый раз ставить подобные вопросы и отвечать на них крайне важно. Поэтому, без изменения подходов к системе контроля и оценки в процессе обучения невозможно достичь поставленных образовательных целей перед яхтингом. [5].

Формирование личности предполагает развитие процесса целеобразования и, соответственно, развития действий субъекта.

Целеустремлённость в учебнопрофессиональной деятельности студентов способность формулировать задачу с определёнными характеристиками, планировать деятельность, выполнять действия согласно потребностям цели, преодолевая сопротивление. Целеустремлённые студенты умеют сознательно планировать деятельность и действия и последовательно выполнять их до достижения цели.[15].

Необходимо так построить учебновоспитательный процесс в вузе, который способствовал бы актуализации студентов к их профессиональной деятельности, развитию личности и побуждал бы их к профессиональной целеустремленности на этапе начального приобретения профессиональных навыков. Целеустремлённость человека не является врождённой чертой: не имеют значения возрастные, гендерные и культурные различия. Это приобретённая черта, и вырабатывается она последовательными действиями. Научиться управлять парусом и парусной яхтой сложный процесс, требующий затрат больших ресурсов, для формирования навыков правильного определения курсов относительно ветра требуется много времени и усилий, хотя это навык которым может обладать абсолютно любой индивид и, отказывая вправе развить его при имеющихся возможностях, он лишает себя источника реализации своих мечтаний.[20].

Необходимо развивать в себе такие черты характера как:

- настойчивость;

-упорство;

-мотивированность;

-четкость восприятия;

-силу воли. [14]

Целеустремлённость это качество, определяемое по результатам его реализации. Только достигая поставленных целей, индивид может приписывать себе данную характеристику.
Так и если человек достиг некоторой цели, был определённый период целеустремлённым, далее прекратил необходимые действия, выбрав пассивное поведение, целеустремлённость будет терять свою силу и о ней нельзя уже заявлять. Развивающая функция целеустремлённости в яхтинге заключается в том, что она дает больше возможностей, сил и способностей переходить на новые уровни освоения яхтинга, формирования его практических навыков, знаний и умений. Студентам необходимо воспроизводить усвоенное, перерабатывать и систематизировать имеющиеся знания, делать выводы, обобщения, в практических условиях учиться применять теоретические знания, что эффективно содействует развитию обучаемого.

Часто преградой к достижению цели является отсутствие мотивации, или её снижение по мере реализации или ещё на стадии планирования. Если долго откладывать реализацию, занимаясь длительным планированием, эмоциональная энергия расходуется - мотивация снижается. Чтобы уменьшить это снижение следует напоминать себе о результатах, планировать промежуточные этапы. Поэтому на начальном этапе освоения яхтинга можно оттачивать навыки постепенно, формируя привычки ежедневными действиями. Постепенно задачи, стоящие перед собой, необходимо усложнять, т.к. длительное выполнения чрезмерно лёгкого задания снижает удовольствие. Итак, постепенно освоив необходимый навык, следует переходить на новую ступень в развитии навыков и умений.

Включая в педагогический процесс занятия яхтингом на факультативной основе, мы создаем развивающую среду, которая помогает студентам освоить новые способы поведения, расширить свои профессиональные знания и навыки, найти им практическое применение. Яхтинг развивает целеустремлённость в учебно-профессиональной деятельности студентов. Участие студентов в крейсерских походах и различных «морских» проектах помогает им приобрести опыт, связанный с организацией коллективной творческой деятельности. Это даёт возможность студентам развить свои профессиональные навыки и личностный опыт, апробировать технологии будущей работы в должности офицера морского флота. Проведенная работа подтверждает, что изменение характера содержания и организации учебных практик студентов углубляет и расширяет их знания в области технологии общения с различными типами личности и характера сверстников, способствует приобретению и развитию нового субъектного опыта профессиональной деятельности. [10,13]. 


\begin{tabular}{|c|c|c|c|c|c|c|}
\hline Impact Factor: & $\begin{array}{l}\text { ISRA (India) } \\
\text { ISI (Dubai, UAE } \\
\text { GIF (Australia) } \\
\text { JIF }\end{array}$ & $\begin{array}{l}=1.344 \\
=0.829 \\
=0.564 \\
=1.500\end{array}$ & $\begin{array}{l}\text { SIS (USA) } \\
\text { PИНЦ (Russia) } \\
\text { ESJI (KZ) } \\
\text { SJIF (Morocco) }\end{array}$ & $\begin{array}{l}=0.912 \\
=\mathbf{0 . 2 0 7} \\
=\mathbf{4 . 1 0 2} \\
=\mathbf{2 . 0 3 1}\end{array}$ & $\begin{array}{l}\text { ICV (Poland) } \\
\text { PIF (India) } \\
\text { IBI (India) }\end{array}$ & $\begin{array}{l}=6.630 \\
=1.940 \\
=4.260\end{array}$ \\
\hline
\end{tabular}

\section{Conclusion}

Исследование не претендует на окончательное решение проблемы поиска путей и средств, способствующих формированию целостно-системной личности широкопрофильного морского специалиста, но актуализирует проблему подготовки специалиста, используя для этого ресурс занятий яхтингом в вузе. Дальнейшее углубленное исследование данной проблемы может осуществляться в направлении изучения влияния яхтинга на студентов, обучающихся по специальностям гуманитарного профиля. [16].

\section{References:}

1. Leontev A.N. (1975) Deyatelnost. Soznanie. Lichnost. M.: Politizdat.

2. Vygotskij L.S. (1934) Myshhlenie i rech. M.L.: Socekgiz.

3. Galperin P.Ya. (1999) Vvedenie v psixologiyu. M.: Knizhnyj dom «Universitet».

4. Reshetova Z.A. (1985) Psixologicheskie osnovy professionalnogo obucheniya. M.: Iz-vo MGU.

5. Reshetova Z.A. (2002) Formirovanie sistemnogo myshleniya $\mathrm{v}$ obuchenii. teoreticheskie osnovy // Formirovanie sistemnogo myshleniya $\mathrm{v}$ obuchenii : uchebnik dlya vuzov / pod red. Z.A. Reshetovoj. - M.: Yuniti-Dana.

6. Reshetova Z.A. (2013) K voprosu o mexanizmax usvoeniya i razvitiya. Nacionalnyj psixologicheskij zhurnal №1(9)/2013, 25-32. doi: 2079-6617/2013.0104

7. Talyzina N.F. (1998) Pedagogicheskaya psixologiya. M.: Akademiya.

8. Davydov V.V. (1992) Psixologicheskaya teoriya uchebnoj deyatelnosti i metodov nachalnogo obucheniya, osnovannyx na soderzhatelnom obobshhenii. T.: Peleng.

9. Ilyasov I.I. (1981) Organizaciya sovmestnoj raboty studentov. (v soavt.). M..

10. Tixomirov O.K. (1975) Psixologicheskie issledovaniya tvorcheskoj lichnosti. M.: Nauka.

11. Asmolov A.G. (1984) Lichnost kak predmet psixologicheskogo issledovaniya. M.: Iz-vo MGU.

12. Samonenko Yu.A. (2001) Psixologiya i pedagogika. M.: Yuniti-Dana.

13. Mishchik SA (2015) Pedagogometrik - science and academic subject. Materialy Mezhdunarodnoy nauchnoy konferenctsii "European Technology in Science" 28.02.2015. ISJ Theoretical \& Applied Science
02 (22): 103-106 Malmö, Sweden. doi: http://dx.doi.org/10.15863/TAS.2015.02.22.17

14. Medvedev V.N. (2017) Yachting - is the factor of development of social activity of students. Isj theoretical \& applied science, 06 (50): 133-138. doi: https://dx.doi.org/10.15863/TAS.2017.06.50.18

15. Medvedev V.N. (2017) Yachting - the condition of forming of the identity of the student. ISJ Theoretical \& Applied Science, 07 (51): 117-122. doi: https://dx.doi.org/10.15863/TAS.2017.07.51.20

16. Medvedev V.N. (2017) Yachting - development of the generalized professional activity of students. ISJ Theoretical \& Applied Science, 08 (52): 108-114. doi: https://dx.doi.org/10.15863/TAS.2017.08.52.17

17. Medvedev V.N. (2017) Yachting - conditions of forming of special technology skills of students of sea higher educational institutions. ISJ Theoretical \& Applied Science, 09 (53): 171176. doi: https://dx.doi.org/10.15863/TAS.2017.09.53.26

18. Medvedev V.N. (2017) Yachting development of the subject relations of professional skills of students. ISJ Theoretical \& Applied Science, 10 (54): 166 - 170. doi: https://dx.doi.org/10.15863/TAS.2017.10.54.27

19. Medvedev V.N. (2017) Yachting - conditions of forming of control professional skills of students of sea specialties. ISJ Theoretical \& Applied Science, 11 (55): 228-233. doi: https://dx.doi.org/10.15863/TAS.2017.11.55.29

20. Medvedev V.N. (2017) Yachting development of commitment in educational professional activity of students. ISJ Theoretical \& Applied Science, 12 (56): 182-187. Soi: http://s-o-i.org/1.1/TAS-12-56-29 Doi: https://dx.doi.org/10.15863/TAS.2017.12.56.29 